\title{
The identification method of pollution origin and degree of the injection well
}

\author{
LIU HONGBO \\ The fifth production plant , Daqing oilfield company. Daqing, 163513, China
}

\begin{abstract}
In order to solve the problem that the pollution causes and the degree of the injection well can not be effectively identified, based on the consideration of the sensitivity of the reservoir and the water quality of injected water. The mathematical models of injection well pollution were established. The causes of pollution and pollution degree were determined.Recommended measures to different factors of pollution are confirmed. It proved that the efficiency of the recommended measures has been greatly improved. Research results show that,according to the degree of pollution to all factors of pollution, the rank from largest to smallest is solid particle, clay swelling, water sensitivity, inorganic scale, acid sensitivity, bacteria, particle migration, velocity sensitivity. Therefore, the major factors of pollution in the reservoir are solid particle and clay swelling.
\end{abstract}

Key words: skin factor; pollution radius; cause of pollution; application efficiency

\section{Introduction}

In the process of oil and gas reservoir development, water injection is an important technical measure to make long term high and stable production of oil well. But the injected water quality, reservoir physical properties, construction and other factors, are easy to cause the formation of pore plugging, causing some damage to the reservoir. At present, the damage degree of reservoir has been studied from two aspects: field test method and mathematical model, However, the research on the recommended measures to determine the degree of damage by reservoir is less ${ }^{[1-2]}$. In this paper, the cause of pollution and pollution degree of injection well, so as to put forward the way to remove the oil layer pollution in the field of practical scale application. Therefore, it provides a reliable theoretical basis and field guidance for the identification of water injection well and the development of injection enhancement measures ${ }^{[3-4]}$.

\section{Analysis of reservoir pollution sources}

According to the analysis of the core well clay, the results show that the, the absolute content of clay in Saertu oil layer in XS area is 5.6\%,the average of the putaohua oil layer is 7.7\%;From the composition of clay, the Saertu oil layer is dominated by illite, which content beteen $56.6 \%$ and $76.1 \%$.The Putaohua reservoir of kaolinite and chlorite content increased significantly, which belongs to the kaolinite clay. The swelling of montmorillonite is not high in Saertu and putaohua oil layer,but it is quite stable in the proportion of each oil group, which content about $20 \%$. According to the analysis of the core well clay, the results show that in the XS area, the performance of the oil reservoir in SA is weak speed sensitivity, weak water sensitivity, strong acid sensitivity and weak alkali sensitivity. ${ }^{[5-6]}$

Suspended solid particles and bacterial particles carried in the water, In the process of displacement, solid particle migration, bacterial reproduction and other hydrocarbon migration channels are blocked, resulting in the reduction of reservoir seepage capacity. A area of Water Quality Monitoring Bulletin shows that oil content, suspended solids content, bacterial content are 
different degrees of excessive, resulting in damage to the reservoir ${ }^{[7]}$. In addition, when injected water and formation water or reservoir is not compatible, especially the type and degree of mineralization vary greatly when injected water meets formation water, inorganic scale is often produced in the reservoir, which leads to the formation of the formation plugging, so that the permeability of the reservoir is decreased.

\section{Determination of identification and damage degree of reservoir pollution}

\subsection{The establishment of mathematical model of skin coefficient}

In order to effectively identify the reasons of reservoir pollution, based on the analysis of the source of the pollution sources, combined with the field data of XS area, the derivation of the literature and theoretical formula, 6 mathematical models of the skin coefficient of 6 pollution factors were established,which were the solid particles, clay swelling, inorganic scale, acid sensitivity, bacteria and particle migration mathematical models.( Table 1)

Table 1 Mathematical models of skin factor statistics on different pollution factors

\begin{tabular}{|c|c|c|}
\hline type & mathematic & process models \\
\hline $\begin{array}{c}\text { acid } \\
\text { sensitivity }\end{array}$ & $S_{\text {acid }}=\left(\frac{1}{1-I_{a}}-1\right)\left(\ln \frac{r_{e}}{r_{w}}-0.75\right)$ & $\begin{array}{c}I_{a}=308.387+27.36 \times K_{a}^{1.059}-18877.258 \times K_{a} / \phi+4828.647 / \phi \\
\quad-25033.947 / \phi^{0.5}-3266.158 / R_{2}+3842.0821 / R_{2}^{0.5} \\
+1906.916 \times\left(1+K_{a}^{0.5}\right) / \phi^{0.5}+2969365.750 \times I S_{1}-6.142 \times I S_{1}{ }^{2} \\
-14.723 \times \lg \left(1+I S_{1}\right)-1979549.625 \times\left(S+I S_{1}+I S_{1} \times I S R\right)+36.248 \times C^{0.5} \\
-11.429 \times C l^{0.5}-19.006 \times \phi-34.343 \times K_{a}+25.643 \times R_{2}\end{array}$ \\
\hline $\begin{array}{l}\text { particle } \\
\text { migration }\end{array}$ & $S=\left(\frac{K_{c}}{K^{\prime}}-1\right) \times \ln \frac{r_{s}}{r_{w}}$ & $r_{s}=\frac{Q_{h} r_{w}}{Q}, Q_{h}=Q-\pi r_{w}^{2} h, K^{\prime}=\frac{2 a_{1} K_{c} r_{s}^{2}}{r_{s}^{2}-r_{w}^{2}} \cdot \ln \frac{r_{s}}{r_{w}}+\frac{2 b K_{c} r_{s}}{r_{s}+r_{w}}+c K_{c}$ \\
\hline $\begin{array}{l}\text { clay } \\
\text { swelling }\end{array}$ & $S=\left(\frac{K_{o}}{K_{d}}-1\right)\left(\ln \frac{r_{e}}{r_{w}}-0.75\right)$ & $\begin{array}{c}C c=1000(658.973 \mathrm{Mt} / \mathrm{Nz}+753.6464 \mathrm{Gl} / \mathrm{Nz} / 595.219 S y+72.2886) \\
K_{d}=6.9807 \times 10^{-2} K_{c}^{1.6016}\left(\frac{0.618 C c+0.8 K_{C}}{140.6257}\right)^{1 / \text { 外粶 }}\end{array}$ \\
\hline bacteria & $S=\left(\frac{K_{o}}{K}-1\right)\left(\ln \frac{r_{e}}{r_{w}}-0.75\right)$ & $\begin{array}{c}R_{k}=\left[0.81 / \lg K_{o}+6.6385 \times 10^{-2} \times \lg T G B-0.4040982\right] \times V_{L} \\
V_{L}=\frac{V_{1}}{\pi h\left(r_{e}^{2}-r_{w}^{2}\right) \phi} K=\left(1-R_{k}\right) \times K_{o}\end{array}$ \\
\hline $\begin{array}{l}\text { inorganic } \\
\text { scale }\end{array}$ & $S=\left(\frac{K_{\text {前 }}}{K_{\text {后 }}}-1\right)\left(\ln \frac{r_{e}}{r_{w}}-\frac{3}{4}\right)$ & $\begin{array}{c}I S_{2}=\lg \left(\mathrm{Ca}^{2+} \times \mathrm{HCO}_{3}^{-}\right)+p H-2.42+0.02 T-1.53 \times 10^{-5} \mathrm{~T}^{2} \\
\quad-6.33 \times 10^{-3} \mathrm{P}-2.02 I^{0.5}+0.7272, I=\frac{1}{2} \sum c_{\mathrm{i}} Z_{i}^{2}, \\
y=4.5805 \times\left(I S_{2}\right)^{2}+28.647 \times\left(I S_{2}\right)+7.6059, n=y / 12, \\
R_{\text {损害率 }}=\mathrm{a}_{2} \mathrm{Cnt} \times 100 \%, K_{\text {后 }}=K_{\text {前 }} \times R_{\text {损害率 }}\end{array}$ \\
\hline $\begin{array}{c}\text { solid } \\
\text { particles }\end{array}$ & $S=\left(\frac{K}{K^{\prime}}-1\right) \times \ln \frac{r_{s}}{r_{w}}$ & $\begin{array}{c}D=r_{w} \times\left[1-\frac{1}{\gamma} \times \ln \frac{0.02 \alpha}{2(1-\alpha) \gamma \ln \left(r_{e} / r_{w}\right)}\right]^{0.5}-r_{w} \alpha=\frac{V / \Delta P}{V^{\prime} / \Delta P^{\prime}}, \\
\gamma=\frac{\pi r_{w}^{2} h \lambda_{v}}{q_{w}}, \phi^{\prime}=\frac{\pi h \phi\left(r_{s}^{2}-r_{w}^{2}\right)-Q_{z} V_{y} \times 10^{-6} / 2.6}{\pi h\left(r_{s}^{2}-r_{w}^{2}\right)} \frac{K}{K^{\prime}}=\left(\frac{\phi}{\phi^{\prime}}\right)^{3}\end{array}$ \\
\hline
\end{tabular}

\subsection{Quantitative determination of reservoir pollution degree}

The nearer the wellbore is, the more serious the pollution is, so the permeability of the polluted zone is changed with the radius. Damage radius can be determined by using the relationship between the skin factor $S_{d}$ and the damage radius $r_{s}$.

$$
S_{d}=\frac{h}{h_{p}}\left\{\left(\frac{K}{K_{w}}\right)^{\frac{r_{s}}{r_{s}-r_{w}}}\left[-E i\left(-\frac{r_{w}}{r_{s}-r_{w}} \ln \frac{K}{K_{w}}\right)+E i\left(-\frac{r_{s}}{r_{s}-r_{w}} \ln \frac{K}{K_{w}}\right)\right]-\ln \frac{r_{s}}{r_{w}}\right\}
$$

( formula 1)

Newton iteration method is used to solve the above equations, and the damage radius can be 
obtained.

$$
\begin{aligned}
& \text { Order } f\left(r_{s}\right)=-E i\left(-\frac{r_{w}}{r_{s}-r_{w}} \ln \frac{K}{K_{w}}\right)+E i\left(-\frac{r_{s}}{r_{s}-r_{w}} \ln \frac{K}{K_{w}}\right)-\left(\frac{K}{K_{w}}\right)^{-\frac{r_{s}}{r_{s} r_{w}}}\left(\ln \frac{r_{s}}{r_{w}}+\frac{h_{p}}{h} S_{d}\right) \\
& \text { That } f^{\prime}\left(r_{s}\right)=\frac{\left\{\left(\frac{K}{K_{w}}\right)^{\frac{r_{s}}{r_{w}+r_{w}}}-\left(\frac{K}{K_{w}}\right)^{\frac{r_{s} s}{r_{s} r_{w}}}\left[1+\left(\ln \frac{r_{s}}{r_{w}}+\frac{h_{p}}{h} S_{d}\right) \frac{r_{w}}{r_{s}-r_{w}} \ln \frac{K}{K_{w}}\right]\right\}}{r_{s}-r_{w}} \\
& \text { Therefore } \quad r_{s n+1}=r_{s n}-\frac{f\left(r_{s n}\right)}{f^{\prime}\left(r_{s n}\right)}
\end{aligned}
$$

\section{Field application of identification method}

\subsection{Determination of blocking radius of reservoir pollution}

According to the The designed method to the optimization of measures in increasing injection in the first area and the third area of xingnan development area in xingshugang oilfield combined with field data of XS area, the acidification radius is determined for different types of formation. Among them, the acidification radius of the clay mineral is $2.5 \sim 3.0 \mathrm{~m}$, the organic matter is blocked by $0.5 \sim 1.0 \mathrm{~m}$, the slurry is blocked by $0.8 \sim 1.2 \mathrm{~m}$, and the mechanical impurity is blocked by $2 \sim 3 \mathrm{~m}$. In order to effectively remove the oil reservoir blockage, the maximum pollution radius can be considered as $3 \mathrm{~m}$. That is, a certain level of pollution radius is less than $3 \mathrm{~m}$, the recommended measures for acidification; pollution radius is greater than $3 \mathrm{~m}$, then the use of a greater strength of the fracturing measures.

\subsection{Field application verification}

At present, the method has been applied in the XS area to solve the blocking measures, and the identification of the causes and the degree of pollution in the 145 layers of the 49 injection well is given and the recommended measures is given at the same time. After the implementation of the measures for the implementation of the 49 wells, the effectiveness of the recommended measures was $93.88 \%$, and the efficiency increased 5.88 percentage points compared with the previous measures.

Table 2 the results of field application of pollution cause and pollution degree method

\begin{tabular}{|c|c|c|c|c|c|c|c|}
\hline $\begin{array}{c}\text { Serial } \\
\text { number }\end{array}$ & $\begin{array}{c}\text { Injection } \\
\text { well }\end{array}$ & section & main pollution type & $\begin{array}{c}\text { contaminated } \\
\text { radius } \\
(\mathrm{m})\end{array}$ & $\begin{array}{c}\text { recommended } \\
\text { measure }\end{array}$ & $\begin{array}{c}\text { measure } \\
\text { time }\end{array}$ & $\begin{array}{c}\text { measure effect } \\
\text { evaluation }\end{array}$ \\
\hline 1 & $31-330$ & S311S322 & Particle migration & 0.44 & acidification & 201608 & effective \\
\hline 2 & $31-330$ & S341S353 & Particle migration & 0.48 & acidification & 201608 & effective \\
\hline 3 & $31-330$ & S361S361 & Particle migration & 0.48 & acidification & 201608 & effective \\
\hline 4 & $31-330$ & S371S3111 & Particle migration & 0.35 & acidification & 201608 & effective \\
\hline 5 & $22-W 471$ & S211S272 & Inorganic scale & 0.48 & acidification & 201606 & effective \\
\hline 6 & $22-W 471$ & S2111S2161 & Solid particles & 9.36 & acidification & 201606 & effective \\
\hline 7 & $22-W 471$ & S361S3112 & Inorganic scale & 0.49 & acidification & 201606 & effective \\
\hline 8 & $2-132$ & S222S241 & acid sensitivity & 0.10 & acidification & 201607 & effective \\
\hline 9 & $2-132$ & S251S282 & Clay swelling & 0.38 & acidification & 201607 & effective \\
\hline 10 & $2-132$ & S283S2111 & Clay swelling & 0.37 & acidification & 201607 & effective \\
\hline 11 & $2-131$ & S271S291 & Inorganic scale & 0.36 & acidification & 201608 & effective \\
\hline$\ldots$ & $\ldots$ & $\ldots$ & $\ldots$ & $\ldots$ & $\ldots$ & & \\
\hline 141 & $10-241$ & P1111P1122 & Inorganic & 0.26 & acidification & 201610 & effective \\
\hline 142 & $10-241$ & P1323P1422 & Inorganic & 2.11 & acidification & 201610 & effective \\
\hline 143 & D1-244 & S211S2161 & Inorganic scale & 0.46 & acidification & 201610 & effective \\
\hline 144 & $22-S 11$ & S211S243 & acid sensitivity & 0.48 & acidification & 201607 & effective \\
\hline 145 & $22-S 11$ & S251S283 & Particle migration & 0.61 & acidification & 201607 & effective \\
\hline
\end{tabular}




\section{Conclusion}

In this paper, we put forward the concept of total skin factor of reservoir, which is defined as the skin factor of various types of reservoir damage.

This paper systematically discusses the formation cause of contaminated reservoir, and combined with the characteristics of reservoir and water quality in XS area, the mathematical model of skin coefficient and pollution radius is established, which not only can effectively identify the cause of formation of reservoir pollution, but also can quantitatively describe the degree of reservoir pollution.

After the application of the mathematical model of skin factor calculation, there are six reasons for the reservoir contamination in XS area, from the largest to smallest, solid particles, clay swelling, inorganic scale, acid sensitivity, bacteria and particle migration. Among them, the main pollution factors are the expansion of solid particles and clay.

\section{Acknowledgments}

This work is supported by PetroChina Innovation Foundation (2016D-5007-0201).

\section{References}

[1] Xu Jianjun, Xu Yan-chao, Yan, Li-me,et.al. Research on the method of optimal PMU placement. International Journal of Online Engineering,v9, S7, p24-29, 2013 [2] Xu Jian-Jun, Y. Y. Zi., Numerical Modeling for Enhancement of Oil Recovery via Direct Current. International Journal of Applied Mathematics and Statistics, 2013, 43 (13): 318-326

[3] Longchao, Zhu Jianjun, Xu; Limei, Yan. Research on congestion elimination method of circuit overload and transmission congestion in the internet of things. Multimedia Tools and Applications, p 1-20, June 27, 2016

[4] Yan Limei, Zhu Yusong, Xu Jianjun,et.al. Transmission Lines Modeling Method Based on Fractional Order Calculus Theory. TRANSACTIONS OF CHINA ELECTROTECHNICAL SOCIETY, 2014 ,Vol.29,No. 9:260-268 (In Chinese)

[5] YAN Li-mei, CUI Jia, XU Jian-jun,et.al. Power system state estimation of quadrature Kalman filter based on PMU/SCADA measurements. Electric Machines and Control. 2014, Vol.18 No.6,: 78-84. (In Chinese)

[6] YAN Limei,XIE Yibing, XU Jianjun, et.al. Improved Forward and Backward Substitution in Calculation of Power Distribution Network with Distributed Generation. JOURNAL OF XI'AN JIAOTONG UNIVERSITY,2013, Vol.47, No.6, p117-123. (In Chinese)

[7] Xu J.J., Gai D., Yan L.M. A NEW FAULT IDENTIFICATION AND DIAGNOSIS ON PUMP VALVES OF MEDICAL RECIPROCATING PUMPS. Basic \& Clinical Pharmacology \& Toxicology, 2016,118 (Suppl. 1), 3-117 